NEVES, L.G.; LEAL, N.R.; RODRIGUES, R.; PEREIRA, N.E. Estimativa de parâmetros genéticos e correlação entre componentes de resistência à traça-dotomateiro em progênies de Lycopersicon esculentum x L. hirsutum f. glabratum. Horticultura Brasileira, Brasília, v. 21, n. 3, p. 458-461, julho-setembro 2003.

\title{
Estimativa de parâmetros genéticos e correlação entre componentes de resistência à traça-do-tomateiro em progênies de Lycopersicon esculentum x L. hirsutum f. glabratum
}

\author{
Leonarda G. Neves; Nilton R. Leal; Rosana Rodrigues; Norma Eliane Pereira ${ }^{1}$ \\ UENF, Av. Alberto Lamego, 2000, 28013-600 Campos dos Goytacazes-RJ; E-mail: neves@uenf.br.
}

\begin{abstract}
RESUMO
Avaliou-se o comportamento de cinco progênies $\mathrm{F}_{3}$ do cruzamento entre Lycopersicon esculentum cv. IPA-6 e L. hirsutum f. glabratum PI 134418, quanto ao ataque da traça-do-tomateiro, Tuta absoluta (Meyrick) (Lepidoptera: Gelechiidae), com base na determinação dos parâmetros genéticos e nas correlações entre componentes de resistência. Foi avaliada a área foliar danificada por $T$. absoluta, em $\mathrm{cm}^{2}$; o número de tricomas tipo VI, por $\mathrm{mm}^{2}$, nas faces adaxial e abaxial; e o número de galerias por folíolo. As seleções utilizando-se os parâmetros área foliar danificada, número de tricomas tipo VI das faces adaxial e abaxial das folhas e número de galerias de T. absoluta têm grandes possibilidades de proporcionarem ganhos genéticos futuros, por apresentarem ampla variabilidade genotípica, com valores elevados de coeficiente de determinação genotípica e magnitude superior à unidade para o índice de variação. As correlações fenotípicas entre a área foliar consumida por $T$. absoluta e as densidades de tricomas das faces adaxial e abaxial das folhas foram negativas e significativas, assim como entre a área foliar e o número de galerias feitas pela T. absoluta por folíolo. Também verificaram-se correlações significativas e positivas para as densidades de tricomas nas duas faces foliares. Isso indica que a resistência está diretamente relacionada a maiores quantidades de tricomas foliares do tipo VI, e ainda que genótipos com valores de DANO alto possuam menor número de galerias.
\end{abstract}

Palavras-chave: Tuta absoluta, resistência a pragas, tricomas, variabilidade genotípica.

\begin{abstract}
Genetic parameters and correlation among progenies of Lycopersicon esculentum $\times$ L. hirsutum f. glabratum for resistance to tomato pinworm

The reaction to the tomato pinworm (Tuta absoluta) of five $\mathrm{F}_{3}$ progenies of the crossing between Lycopersicon esculentum cv. IPA6 and L. hirsutum f. glabratum PI 134418 was evaluated. The fouler area injured by T. absoluta in $\mathrm{cm}^{2}$, number of fouler trichomes type VI per $\mathrm{mm}^{2}$ on adaxial and abaxial faces and the number of galleries per leaflet were evaluated. Injured fouler area, number of fouler trichomes type VI of adaxial and abaxial faces and the number of galleries of T. absoluta have great possibilities of future genetic gains, once they present wide genotype variability, with elevated values of determination coefficient and magnitude higher than the unit for the variation index. The phenotypic correlation among the fouler area consumed by $T$. absoluta and the trichomes densities of the adaxial and abaxial faces of the leaves were negative and significant, as well as between the fouler area and the number of mines of T. absoluta per leaflet. A positive and significant correlation for trichomes densities on both fouler faces was also verified. This suggests that the resistance is related to a greater number of foliar trichomes type VI.
\end{abstract}

Keywords: Tuta absoluta, pest resistance, trichomes, genotypic variability.

(Recebido para publicação em 28 de novembro de 2001 e aceito em 22 de abril de 2003)

\begin{abstract}
A traça-do-tomateiro (Tuta absoluta), inseto que se encontra nas principais áreas de cultivo, sendo considerada uma das pragas mais importantes da cultura, tem sido controlada por meio de inseticidas. As perdas de produção podem chegar a níveis preocupantes, pois elevadas populações desse inseto podem destruir até $100 \%$ da área foliar da planta (Maluf et al., 1997). O uso de fontes de resistência a partir de espécies silvestres tem sido cada vez mais freqüente em programas de melhoramento do tomateiro, visando resgatar genes perdidos no processo de domesticação. A espécie L. hirsutum f. glabratum tem se destacado por apresentar resistência a diversos insetos, dentre eles a Tuta absoluta (Meyrick) (Lepidoptera: Gelechiidae), e vem sendo amplamente utilizada como fonte de re-
\end{abstract}

sistência em programas de melhoramento que visam introgredir genes de resistência a insetos (Barone et al., 1989).

As metil-cetonas, 2-tridecanona e 2undecanona, que estão presentes, principalmente, no ápice da estrutura foliar denominada tricoma glandular do tipo VI, são abundantes na espécie L. hirsutum f. glabratum, e têm sido o principal fator que proporciona resistência à T. absoluta (Maluf \& Barbosa, 1996). O presente trabalho objetivou avaliar o comportamento de cinco cultivares comerciais e cinco progênies $\mathrm{F}_{3}$ do cruzamento entre Lycopersicon esculentum (cv. IPA-6) e L. hirsutum f. glabratum (PI 134418), em relação à traça-do-tomateiro, com base em estimativas de parâmetros genéticos e correlações entre componentes de resistência.

\section{MATERIAL E MÉTODOS}

O trabalho foi conduzido em casa de vegetação, em área do convênio UENF/ PESAGRO-RIO, na Estação Experimental de Campos, em Campos dos Goytacazes, RJ.

As famílias $\mathrm{F}_{3}$ utilizadas foram selecionadas com base em resultados obtidos por Pereira (1998). Esse material genético foi originado a partir da técnica de hibridação artificial e interespecífica entre L. esculentum, genitor agronomicamente comercial, e L. hirsutum f. glabratum, genitor com fonte de resistência a T. absoluta. O delineamento experimental foi blocos ao acaso, com 12 tratamentos (genótipos) e três repetições. 
Para fornecer ovos e permitir as avaliações da resistência à traca-do-tomateiro foi instalada criação, baseando-se nos métodos propostos por Ferrara (1995) e Pereira (1998). A criação foi iniciada com a coleta de folhas minadas com larvas de Tuta absoluta em plantios comerciais no município de São João da Barra, RJ.

Para avaliação do dano, utilizaramse de tubos de diálise, que consistem em uma membrana de celulose transparente, de $12 \mathrm{~cm}$ de comprimento e $4,5 \mathrm{~cm}$ de diâmetro, vedada nas extremidades por uma espuma de 1,5 cm de espessura. Em uma das espumas foi feito um corte de aproximadamente $1 \mathrm{~cm}$ em direção ao centro, para permitir a entrada do folíolo a ser analisado. Este método é uma adaptação dos métodos propostos por Dimock et al. (1986) e por Pereira (1998).

A avaliação do dano iniciou-se 30 dias após o transplantio. Para tanto, com o auxílio do pincel fino foi colocada uma larva de primeiro ínstar, recém eclodida, sobre a face adaxial de um folíolo da quinta folha de cada genótipo, a qual foi imediatamente inserida em tubo de diálise. Após 15 dias, o tubo de diálise foi retirado. O dano foi representado pela área foliar consumida e quantificado por meio de paquímetro digital (Pereira,1998).

Efetuaram-se contagens dos números de galerias feitas pela larva no folíolo central da quinta folha de cada genótipo. Quantificaram-se os tricomas foliares tipo VI das faces abaxial e adaxial de folíolos retirados do meio da $5^{\text {a }}$ folha, a partir do meristema apical, de cada genótipo estudado (Pereira, 1998). Depois de cortado, o pecíolo foi envolvido por algodão umedecido com solução de sacarose a 10\%, coberto por papel laminado e devidamente identificado. Devido à grande destruição de tricomas na face inversa a que está sendo avaliada, foram retirados dois folíolos por genótipo, sendo um para contagem de tricomas da face adaxial e outro para a abaxial.

Os folíolos foram transportados sobre gelo forrado com papel toalha dentro de embalagem térmica. Para a contagem, utilizou-se microscópio estereoscópico Zeiss (Stereomicroscope Stemi SV11), com um aumento de 50 vezes, e campo de visão de $4 \mathrm{~mm}^{2}$. Foram feitas três repetições de contagem em cada face do folíolo. Os resultados apresentados foram obtidos a partir da média dessas três repetições.

As médias fenotípicas foram utilizadas na estimação dos seguintes parâmetros genéticos, baseados em Cruz \& Regazzi (1997):

Variância fenotípica:

$$
\hat{\sigma}_{\mathrm{f}}^{2}=\stackrel{\mathrm{QMG}}{\mathrm{B}}
$$

Variância ambiental:

$$
\stackrel{\wedge}{\sigma_{\mathrm{e}}^{2}}=\mathrm{QMR} ;
$$

Variabilidade genotípica:

$$
\begin{aligned}
& \wedge \\
& \Phi g=\frac{\mathrm{QMG}-\mathrm{QMR} ;}{\mathrm{b}}
\end{aligned}
$$

Coeficiente de determinação genotípica:

$$
\mathrm{H}^{2}=\frac{\Phi \mathrm{G}}{\mathrm{QMG} / \mathrm{b}} ;
$$

Coeficiente de variação experimental:

$$
\mathrm{CV} e=\frac{\sqrt{\mathrm{QMR}}}{\mathrm{m}} \times 100
$$

Coeficiente de variação genotípica:

$$
\operatorname{CVg}=\frac{\sqrt{\Phi_{g}}}{\mathrm{~m}} \times 100
$$

Índice de variação:

$$
\hat{\boldsymbol{I}}_{\mathrm{v}}=\mathrm{CVg} / \mathrm{CV} e
$$

Estimativas dos coeficientes de correlação fenotípica de Pearson (r), com base nas médias de repetições, foram obtidas por meio das expressões:

$$
\mathrm{r}_{(\mathrm{x}, \mathrm{y})}=\operatorname{Cov}(\mathrm{x}, \mathrm{y}) / \sqrt{\sigma_{x} \times \sigma_{y}},
$$

onde: $r_{(x, y)}=$ correlação entre os caracteres $\mathrm{x}$ e $\mathrm{y}$;

$\operatorname{Cov}_{(\mathrm{x}, \mathrm{y})}=$ covariância entre os caracteres $\mathrm{x}$ e $\mathrm{y}$;

$\sigma_{\mathrm{x}}$ e $\sigma_{\mathrm{y}}=$ desvio-padrão dos caracteres x e y, respectivamente.

A significância dos coeficientes de correlação fenotípica foi verificada pelo teste " $\mathrm{t}$ " e o coeficiente de determinação (r²) (Cruz \& Regazzi, 1997).

\section{RESUTADOS E DISCUSSÃO}

As características densidade de tricoma do tipo VI da superfície abaxial e número de galerias feitas pela $T$. absoluta apresentaram ampla variabilidade genotípica ( $\mathrm{Fg}$ ), com valores para o coe- ficiente de determinação genotípica $\left(\mathrm{H}^{2}\right)$ superiores a $90 \%$ e magnitudes do índice de variação $(\boldsymbol{I} v)$ superiores à unidade. Assim, para essas características, métodos simples de seleção seriam suficientes para se obterem ganhos satisfatórios nas próximas gerações (Tabela 1).

Para as características área foliar consumida por T. absoluta e densidade de tricoma do tipo VI da superfície adaxial os valores de $\mathrm{H}^{2}$ foram superiores a $82 \%$ e também poderão propiciar a obtenção de ganhos genéticos. Essas características, apesar dos menores coeficientes de determinação obtidos (Tabela 1), possuem ampla variabilidade genética e índices de variação acima da unidade. Por conseguinte, ganhos genéticos significativos também poderão ser obtidos para essas características, por meio de métodos simples de seleção.

Verificou-se correlação negativa e significativa entre os caracteres área foliar consumida e número de galerias feitas pela T. absoluta, indicando que quanto maior a área foliar consumida menor foi o número de galerias produzidas, demonstrando que genótipos resistentes, como $L$. hirsutum f. glabratum e determinadas famílias $\mathrm{F}_{3}$ foram capazes de restringir $\mathrm{o}$ desenvolvimento da traça (Tabela 1).

Em um estudo semelhante a este por também serem utilizadas lagartas de $T$. absoluta recém eclodidas, e em confinamento com folhas de $L$. esculentum e L. hirsutum f. glabratum, verificou-se a redução da viabilidade pela densidade de tricoma do tipo VI da superfície adaxial e efeitos que caracterizaram a ocorrência de antibiose relacionada a interação T. absoluta e L. hirsutum f. glabratum PI 134417 (Giustolin e Vendramim, 1994). Eigenbrode \& Trumble (1993), também em um estudo sobre o mecanismo de resistência por antibiose, entre L. hirsutum f. glabratum PI 134418 e Spodoptera exigua (Hübner), relataram uma altíssima mortalidade da praga em estudo. Conclui-se que o desenvolvimento, a fecundidade e a taxa de mortalidade de diversos insetos artrópodes são restringidos, quando esses insetos são alimentados com folhas de L. hirsutum $f$. glabratum (Weston et al., 1989).

As correlações entre o caráter área foliar consumida por T. absoluta e densidade de tricoma do tipo VI da superfície adaxial e abaxial, foram negativas e significativas (Tabela 1), evidenciando que os genótipos com maiores densida- 
Tabela 1. Estimativa de parâmetros genéticos e correlação entre componentes de resistência à traça do tomateiro, em seis cultivares comerciais de L. esculentum e cinco progênies $\mathrm{F}_{3}$ do cruzamento entre 'IPA-6' (L. esculentum) e PI 134418 (L. hirsutum). Campos dos Goytacazes, UENF, 2000.

\begin{tabular}{|c|c|c|c|c|c|c|c|c|c|c|c|}
\hline \multirow{2}{*}{$\begin{array}{l}\text { Caracte- } \\
\text { rísticas }^{1 /}\end{array}$} & \multicolumn{5}{|c|}{ Parâmetros } & \multirow{2}{*}{$\begin{array}{c}\text { Caracterís- } \\
\text { ticas }^{1 /}\end{array}$} & \multicolumn{5}{|c|}{ Parâmetros } \\
\hline & $\sigma_{f}^{2} \mathbf{H}$ & $\sigma_{a}^{2}$ & $\Phi \mathbf{g}$ & $\mathrm{H}^{2}$ & IV & & $\sigma_{(x)}^{2}$ & $\sigma^{2}(m$ & Cov & $r$ & $\mathbf{r}^{2}$ \\
\hline DN & 3,84 & 0,67 & 3,17 & 82,58 & 1,26 & DN $x$ TAD & 3,84 & 9,28 & $-4,22$ & $0,71^{* *}$ & $0,71^{* *}$ \\
\hline TAB & 9,55 & 0,66 & 8,89 & 93,0 & 2,11 & $\mathrm{DN} \times \mathrm{TAB}$ & 3,84 & 9,55 & $-5,00$ & $-0,82^{* *}$ & 0,68 \\
\hline TAD & 9,28 & 1,10 & 8,18 & 88,12 & 1,57 & $D N \times N G$ & 3,84 & 0,83 & $-1,60$ & $-0,89^{* *}$ & 0,79 \\
\hline \multirow[t]{3}{*}{ NG } & 0,80 & 0,03 & 0,81 & 96,77 & 3,17 & TAD $\times$ TAB & 9,28 & 9,55 & $+8,94$ & $+0,95^{* *}$ & 0,90 \\
\hline & & & & & & TAD $\times$ NG & 9,28 & 0,83 & $+2,57$ & $+0,92^{* *}$ & 0,85 \\
\hline & & & & & & $\mathrm{TAB} \times \mathrm{NG}$ & 9,55 & 0,83 & $+2,71$ & $+0,96^{* *}$ & 0,92 \\
\hline
\end{tabular}

$* *=$ diferença significativa ao nível de $1 \%$ pelo teste $\mathrm{t} ;{ }^{1 /} \mathrm{DN}=$ área foliar consumida por T. absoluta $\mathrm{em} \mathrm{cm}^{2} ; \mathrm{TAB}=$ densidade de tricoma foliar tipo $\mathrm{VI} / \mathrm{mm}^{2}$ na superfície abaxial da $5^{\text {a }}$ folha; $\mathrm{TAD}=$ densidade de tricoma foliar tipo $\mathrm{VI} / \mathrm{mm}^{2}$ na superfície adaxial da $5^{\text {a }}$ folha; $\mathrm{e}$

$\mathrm{NG}=$ número de galerias feita por T. absoluta no período de incubação. Variância fenotípica: $\sigma_{\mathrm{a}}^{2} \wedge$ Variância ambiental: $\sigma_{\mathrm{a}}^{2} \wedge$ Variabilidade genotípica: $\Phi$ g Coeficiente de determinação genotípica: $\mathrm{H}^{2}$ Índice de variação: $I_{v}$ Coeficiente de correlação: (r) Coeficiente de determinação: $\left(\mathrm{r}^{2}\right)$

de de tricomas do tipo VI em ambas as faces das folhas, terão menor área foliar consumida. Isto indica que esse tipo de tricoma é um fator de resistência para a traça do tomateiro.

Farrar Jr. \& Kennedy (1987) quantificaram a mortalidade de larvas de Heliothis zea (Baddie) (Lepdoptera: Noctuidae), quando essas se alimentavam com L. esculentum e L. hirsutum $\mathrm{f}$. glabratum PI134417. Foram usados folíolos desses genótipos com tricomas do tipo VI e retirados esses tricomas. Os autores verificaram maior mortalidade de $H$. zea onde os tricomas não haviam sido retirados.

Os resultados do presente estudo também revelaram correlações positivas e altamente significativas entre tricomas do tipo VI, tanto da face adaxial, quanto da abaxial e o número de galerias feitas pela traça. A 2-tridecanona, contida na ponta de tricomas do tipo VI, é tido como o principal fator de resistência a insetos-pragas que insidem na espécie L. hirsutum f. glabratum, reafirmando, dessa forma, a estrutura tricoma tipo VI como fator de resistência (Weston et al., 1989; Farrar Jr. \& Kennedy, 1991; Giustolin \& Vendramim, 1996; Maluf, 1997; Pereira et al., 2000).

Pode-se concluir que o maior número de galerias, em vários locais distintos da folha, foi decorrência da tentativa do inseto de se alimentar, uma vez que esse parece estar encontrando barreiras pela associação tricomaaleloquímicos.

A correlação fenotípica dos tricomas da face adaxial e abaxial foi positiva e significativa (Tabela 1), mostrando que quanto maior a média de tricomas do tipo VI para uma face da folha, também será maior para a outra face, para os genótipos tidos como superiores neste estudo. Esta correlação entre os valores de densidade de tricoma do tipo VI da superfície adaxial e da superfície abaxial indica que esses caracteres estão sob o mesmo controle genético, o que caracteriza um possível efeito pleiotrópico, ou mesmo, que os genes que controlam os dois caracteres estariam em um mesmo cromossomo e não segregariam independentemente, o que caracterizaria a ligação gênica (Rick \& Butler, 1956).

\section{AGRADECIMENTOS}

Os autores agradecem ao técnico agrícola José Manoel de Miranda pelo auxílio na execução do trabalho; ao técnico de nível superior Alexandre Pio Viana, pelo auxílio na análise estatística e ao professor Messias Gonzaga Pereira, pelas sugestões.

\section{LITERATURA CITADA}

BARONE, G.H.; PARRA, S.A.; VALLEJO, A.F. Evaluacion de especies silvestres de Lycopersicon sp., como fuente de resistência a Scrobipalpula (Meyrick) y su intento de transferência a Lycopersicon esculentum Mill. Acta Agronomica, v. 39, p. 34-45, 1989.

CRUZ, C.D., REGAZZI, A.J. Modelos biométricos aplicados ao melhoramento genético. 1. ed. Viçosa: UFV, 1994. 390 p.

DIMOCK, M.B.; LAPOINTE, S.L.; TINGEY, W.M. Solanum neocardenasii: A new source of potato resistance to the colorado potato beetle (Coleoptera: Chrysomelidae). Journal of Economic Entomology., v. 79, n. 5, p. 1269-1275, 1986.

EIGENBRODE, S.D.; TRUMBLE, J.T. Antibiose to beet armyworm (Spodoptera exigua) in Lycopersicon acessions. HortScience, v. 28, n. 9, p. 932-934, 1993.
FARRAR JR, R.R.; KENNEDY, G.G. 2undecanona a constituent of the glandular trichomes of Lycopersicon hirsutum $\mathrm{f}$. glabratum: Effects on Heliothis zea and Manduca sexta growth and survival. Entomologia Experimentalis et Applicata, Dordrecht, v. 43, p. 17-23, 1987. FARRAR JR, R.R.; KENNEDY, G.G. Insect and mite resisteance in tomato. In: Prof. Kalloo (ed) Monographs on Theoretical and Applied Genetics 14. Genetic Improvement of Tomato., Berlin: Springer-Verlag, v. 47, p. 121-142, 1991.

FERRARA, F.A.A. Avaliação do componente principal sintético do feromônio sexual de Tuta absoluta (Meyrick) (Lepidoptera: Gelechiidae). Viçosa-MG, 1995. 52 p. (Tese mestrado).

GIUSTOLIN, T.A.; VENDRAMIM, J.D. Efeitos de duas espécies de tomateiro na biologia de Scrobipalpuloides absoluta (Meyrick). Brasil: Anais da Sociedade de Entomologia, , v. 23, n. 3 , p. 511-517, 1994.

GIUSTOLIN, T.A.; VENDRAMIM, J.D. Efeito dos aleloquímicos 2-tridecanona e 2-undecanona na biologia de Tuta absoluta (Meyrick). Brasil: Anais da Sociedade de Entomologia, v. 25, n. 3, p. 417-421, 1996.

MALUF, W.R.; BARBOSA, L.V. Heridensidade de tricoma do tipo VI da superfície abaxialility of 2tridecanone-mediated arthropod resistance in na interspecific segregating generation of tomato. Brasil: Brazilian Journal of Genetics, v. 19, p. 465-468, 1996. MALUF, W.R.; BARBOSA, L.V.; SANTA-CECÍLIAL.V.C. 2-Tridecanona-mediated mechanismo of resistance to the South American tomate pinworm Srobipalpuloides absoluta (Meyrick, 1917) (Lepidoptera- Gelechiidae) in Lycopersicon spp. Euphytica, v. 93, p. 189-194, 1997.

PEREIRA, N.E. Estudos genéticos da resistência à traça do tomateiro (Tuta absoluta) no cruzamento de Lycopersicon esculentum $x$ L hirsutum f. glabratum. Campos dos Goytacazes: UENF, 1998. 110 p. (Tese doutorado).

PEREIRA, N.E.; LEAL, N.R.; PEREIRA, M.G Controle genético da concentração de 2tridecanona e de 2-undecanona em cruzamentos interespecíficos de tomateiro. Bragantina, Campinas, v. 59, n. 2, p. 165-172, 2000.

RICK, C.M.; BUTLER, L. Cytonenetics of the Tomato. Advances in Genetics, 1956, p. 382. WESTON, P.A.; JOHNSON, D.A.; BURTON, H.T.; SNYDER J.C. Trichome secretion composition, trichome densities, and spider mite resistance of tem accessions of Lycopersicon hirsutum. Journal of the American Society for Horticultural Science, v. 114, n. 3, p. 492-498, 1989. 